\title{
Macroinvertebrate data of the Belgian River Meuse from 1998 to 2011
}

\author{
Adrien Latli (iD, Frédéric Chérot \& Patrick Kestemont
}
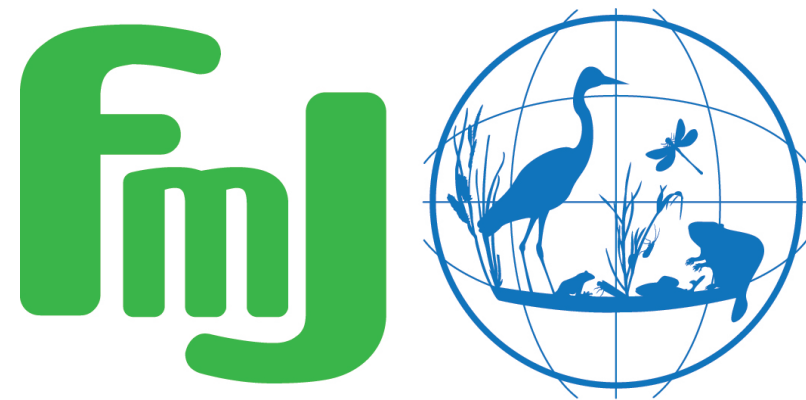

Freshwater Metadata Journal 



\title{
Macroinvertebrate data of the Belgian River Meuse from 1998 to 2011
}

\author{
Adrien Latli ${ }^{1}$ (iD , Frédéric Chérot ${ }^{2}$ \& Patrick Kestemont ${ }^{1}$ \\ 1 University of Namur, Namur, Belgium; corresponding author: adrien.latli@unamur.be \\ 2 SPW Wallonie, Namur, Belgium
}

Please cite this paper as follows: Latli, A., Chérot, F. \& Kestemont, P., 2018. Macroinvertebrate data of the Belgian River Meuse from 1998 to 2011. Freshwater Metadata Journal 34: 1-5.

https://doi.org/10.15504/fmj.2018.34

Received: 2018-06-04 / Published: 2018-09-28

\section{Keywords}

Meuse, macroinvertebates, river

\section{Short description of the dataset/summary}

Between 1998 and 2011 the SPW-DEMNA sampled macroinvertebrates in 3 reaches of the River Meuse (Hastière, Andenne, Lixhe) with a protocol adapted for deep rivers.

Environmental and fish data for the Meuse are also available as separate datasets.

\section{General information}

dataset entry ID:

name of the dataset:

full name of the dataset:

dataset short name:

type of dataset:

data type:
SF_7

Macroinvertebrate data of the Belgian River Meuse from 1998 to 2011

Meuse River macroinvertebrate dataset

species distribution data

point data/observation data

science keywords according to GCMD:

topic:

Terrestrial Hydrosphere

ISO topic category according to ISO 19115:

Biota

INSPIRE keywords according to GEMET:

Environmental monitoring facilities, Species distribution

own science keywords:

related project:

Macroinvertebrate, River Meuse, invasive, long term monitoring

Planctonic resources decrease, and habitat alterations, which consequences for the functioning of communities? University of Namur 
funding:

We would like to thank the SPW (Belgium)for providing the data corresponding to their Meuse River monitoring programs. This work was funded by the University of Namur.

\section{Technical and administrative specifications}

$\begin{array}{ll}\text { data format: } & \text { Excel } \\ \text { operating system: } & \text { Win } 7 \\ \text { data language: } & \text { English } \\ \text { current access level: } & \text { web (public) } \\ \begin{array}{c}\text { currently available through GBIF: } \\ \text { exchange planned: }\end{array} & \text { no } \\ \text { data in data repository: } & \text { no } \\ \text { no }\end{array}$

Do you plan to publish the data on the Freshwater Biodiversity Data Portal:

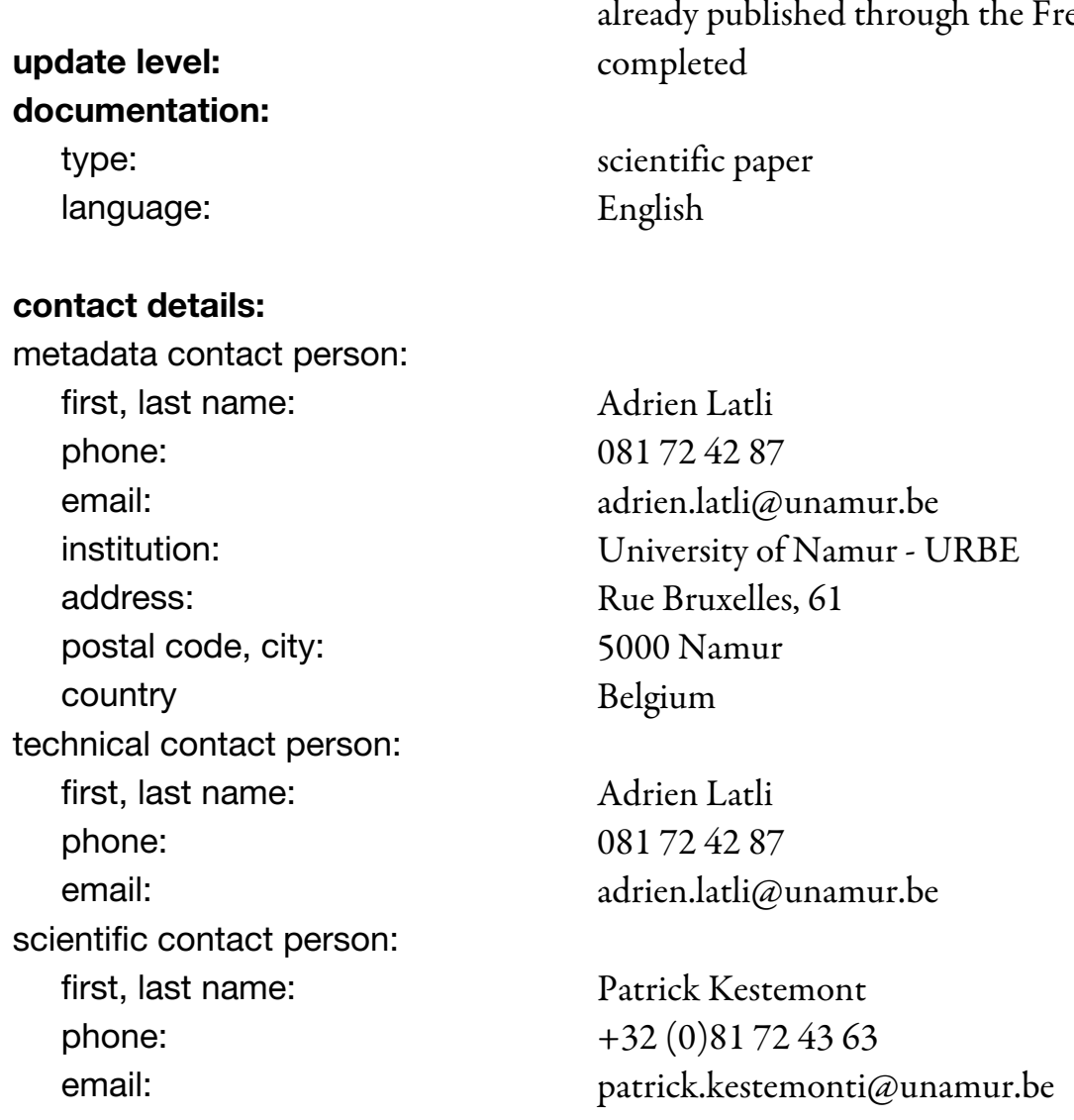

\section{Intellectual property rights and citation}

dataset creator (data compiler):
contact name:
Latli Adrien
contact email:
adrien.latli@unamur.be; patrick.kestemont@unamur.be
contact institution:
University of Namur

data contributors to/owners of this dataset:

number:

multiple

2

data contributor/owner 1:

contact name:

Chérot Frédéric 
contact email: contact institute:

criteria for using this part of the dataset:

The dataset is publicly available (data portal, data archive) and can be used without restrictions, but dataset creator/data contributors must be informed prior to publication. Data must be acknowledged and cited correctly.

data contributor/owner 2:

contact name:

contact email:

contact institute:

criteria for using this part of the dataset:

Adrien Latli

adrien.latli@unamur.be; patrick.kestemont@unamur.be

University of Namur

The dataset is publicly available (data portal, data archive) and can be used without restrictions, but must be acknowledged and cited correctly.

\section{citation of this dataset:}

author(s):

Latli, A. \& Chérot, F.

title and journal (name, number, pages):

Macroinvertebrate data of the Belgian River Meuse from 1998 to 2011.

year:

2017

\section{citation of the metadata:}

author(s):

Latli A., Chérot F. \& Kestemont P.

title and journal (name, number, pages):

Macroinvertebrate data of the Belgian River Meuse from 1998 to 2011.

Freshwater Metadata Journal 34: 1-5

year:

2018

doi:

dataset related references:

reference 1:

author(s):

title:

year:

doi: https://doi.org/10.15504/fmj.2018.34
Latli, A., Descy, J.-P., Mondy, C., Floury, M., Viroux, L., Otjacques, W., Marescaux, J., Depiereux, E., Ovidio, M., Usseglio-Polatera, P. \& Kestemont, P. Long-term trends in trait structure of riverine communities facing predation risk increase and trophic resource decline. Ecological Applications 27(8): 2458-2474. 2017

https://doi.org/10.1002/eap.1621

\section{General data specifications}

regional coverage of the dataset:

spatial extent of the dataset:

continents: regional

Europe

\section{spatial extent (bounding coordinates):}

southernmost latitude $\left[{ }^{\circ}\right]$ :

$50^{\circ} 9^{\prime}$

northernmost latitude $\left[^{\circ}\right]$ :

$50^{\circ} 45^{\prime}$

westernmost longitude $\left[^{\circ}\right]$ :

$4^{\circ} 49^{\prime}$

easternmost longitude $\left[{ }^{\circ}\right]$ :

$5^{\circ} 41^{\prime}$

minimum altitude:

49 metres

maximum altitude:

100 metres

countries:

Europe: Belgium

world climatic regions according to Köppen:

Group C: temperate/mesothermal climates 
freshwater ecoregions of the world (FEOW) according to WWF:

European ecoregions according to Illies (WFD):

Europe: Central \& Western Europe

ecosystem type:

covered timeframe:

\section{Site specifications}

coordinate system/grid data:

datum (e.g. WGS84):

grid data available:

site coding available:

number of sites:

exact number of sites:
Western Plains (ER13)

rivers

$1998-2011$

\section{Biological data}

biological data origin:

organism group addressed: latitude/longitude, format: DMS

projected, UTM

WGS84

no

no

$<100$

3

from sampling,

European survey program

macro-invertebrates (Mollusca, Crayfish, Ephemeroptera, Odonata, Plecoptera, Coleoptera, Trichoptera, Chironomidae)

\section{Sample resolution}

macro-invertebrates:

taxonomic resolution:

level:

family

\section{taxonomic coding:}

taxalist according to:

reference(s):

coding system:

\section{AQEM/Star}

Schmidt-Kloiber, A., Graf, W., Lorenz, A. \& Moog, O. (2006): The

AQEM/STAR taxalist - a pan-European macro-invertebrate ecological database and taxa inventory. Hydrobiologia 566: 325-342.

no coding used

\section{sample specifications:}

specification of method(s) used for sampling and sorting:

Between 1998 and 2011 in 3 reaches of the River Meuse (Hastière, Andenne, Lixhe) a protocol adapted for deep rivers and derived from the IBGA (1997) was used. At these sites, during each sampling campaign, stones near the banks, aquatic vegetation and littoral substrates were sampled with a hand net $(500 \mu \mathrm{m}$ mesh size). The deeper part of the main channel was sampled from a boat using a triangular dredge and three artificial substrates were deployed for one month. Taxa were identified at the family level and abundances were determined with a semi-quantitative estimation ("1" = 1 individual, "2" = 2, "3" = 3, "4" more than 3 and less than 10, "5" = more than 10 and less than 100, "6" > 99).

reference(s): IBGA: "Global Biological Index Adapted to large freshwater rivers", Gay Environnement \& Agence de l?Eau Rhône-Méditerranée-Corse, 1997. 


\section{Other specifications}

GIS layers, shape files related to the dataset:

$\begin{array}{ll} & \text { no data available } \\ \text { availability of photos: } & \text { no } \\ \text { availability of maps: } & \text { no }\end{array}$

quality control procedures:

Were any quality control procedures applied to your dataset?

yes

quality control protocols and comments:

We performed a number of systematic checks using the OpenRefine software.

\section{Acknowledgements}

The authors acknowledge the Belgian Science Policy (Belspo) for funding the SAFRED project (Saving freshwater biodiversity research data - 2015-2018) that allowed processing and publishing the data.

\section{References}

Latli, A., Descy, J.-P., Mondy, C., Floury, M., Viroux, L., Otjacques, W., Marescaux, J., Depiereux, E., Ovidio, M., Usseglio-Polatera, P. \& Kestemont, P., 2017. Long-term trends in trait-structure of riverine communities facing predation risk increase and trophic resource decline. Ecological Applications 27(8): 2458-2474. 2017

https://doi.org/10.1002/eap.1621 